\title{
Chapter 9 \\ Benemérita Universidad Autónoma de \\ Puebla (BUAP). A Transversal Model \\ to Support Educational Continuity \\ Fostering Resilience, Innovation, and Entrepreneurship
}

\author{
Rodolfo Zepeda and Roberto Quintero
}

\begin{abstract}
Throughout its history, Benemérita Universidad Autónoma de Puebla (BUAP), a public institution, has always been a guide of social and economic development of the state of Puebla. From one moment to another, the state was unexpectedly immersed in the Covid-19 pandemic that caused the sudden migration from a mostly face-to-face instructional model to an online one. Immediately, the institution summoned different staff members to define and analyze the situation and then establish actions to guarantee educational continuity.

As part of this analysis, they identified opportunities specifically at the upper secondary level, which includes high school. In particular, one opportunity was to offer entrepreneurship courses in an online format, capitalizing on the experience gained from the undergraduate program. Given the characteristics of the pandemic, the analysis also highlighted that the crisis would have severe economic effects on the students and their families, diminishing their income.

It is estimated that the entrepreneurship education program reached 18,000 people, including students, faculty members, and parents. Over 10,000 more people will be reached throughout the rest of the year. Therefore, it is essential to strengthen the resilience, innovation, and entrepreneurial capacity of the university ecosystem.
\end{abstract}

\subsection{Introduction}

Throughout its history, Benemérita Universidad Autónoma de Puebla (BUAP) has always been a driver of social and economic development in the state of Puebla. The institutional positioning in the state, regional, national, and international

R. Zepeda $(\bowtie) \cdot$ R. Quintero

Benemérita Universidad Autónoma de Puebla, Puebla, Mexico

(C) The Author(s) 2022

F. M. Reimers, F. J. Marmolejo (eds.), University and School Collaborations during a Pandemic, Knowledge Studies in Higher Education 8,

https://doi.org/10.1007/978-3-030-82159-3_9 
environment is associated with the university's contributions through thousands of graduates, basic and applied research, the extension of its services, and several cultural and educational outreach activities.

BUAP guides its work through its strategic agenda, The Institutional Development Plan 2017-2021 (IDP), which establishes its commitment to the members of the university and to society. This includes a commitment to a viable vision of the future and an outline of the path to achieve the desired objectives, closing the gap between the present and the future. The agenda discusses the need for every student to take at least one course online during their time in school, and the goal for 2020 was to develop 1125 additional courses to provide flexibility and increase coverage and access. To achieve this goal, it is necessary to provide the academic, technical, and administrative conditions and to ensure proper preparation for future teachers to teach online.

Suddenly, the institution was immersed in the Covid-19 pandemic, a threat impossible to have predicted. As this came unexpectedly, it forced the university to suddenly migrate from an in-person instructional model to an online one. Without delay, the institution summoned staff to define and analyze the situation and establish courses of action to guarantee educational continuity. As part of this analysis, opportunities were identified specifically at the upper secondary level, which includes high school. One opportunity was to offer entrepreneurship courses in an online format, capitalizing on the undergraduate program where two optional courses are available. Given the characteristics of the pandemic, the analysis also highlighted that the crisis would have economic effects diminishing student incomes.

Some activities were put in motion at the high school level to guarantee academic continuity. The first was to offer the entrepreneurship course online as part of the curriculum, keeping the design principles and basic content and approach used to teach this subject in person. The second activity, "Sal de la Curva" (which translates as "get out of the curve"), consisted of offering a series of mentoring and online master classes to support the students and their environment in the development of self-knowledge, resilience, and their families' and their own well-being. Both activities are fully linked to the mission of the university and can be achieved through collaborating with different units within the BUAP as well as other social and business parties. The background of BUAP will be described in the next section.

\subsection{The Benemérita Universidad Autónoma de Puebla}

The Benemérita Universidad Autónoma de Puebla (BUAP) is a public and autonomous institution consolidated at a national level. The university is committed to the comprehensive education of professionals as well as critical and reflexive citizens at the middle, higher, and postgraduate levels of education, who can generate, adapting, recreating, innovating, and applying knowledge of quality and social relevance. 
Founded in the sixteenth century by the Society of Jesus, the institution was recognized as University of Puebla in 1937, and it became autonomous in 1956. In 1963, a reform was approved that underscored its secular and public character. On April 21,987, the State Congress of Puebla recognized the University's many contributions to science and culture in the state declaring it "Benemerita" (meritorious).

BUAP encourages research, creation, and dissemination of knowledge as well as promotes inclusion and equal opportunities to students. It also contributes as a community of knowledge to the development of art and culture in addition to economic, environmental, social, and political solutions for the region and the country. The university's activities are carried out with transparency and accountability, based on ethical principles oriented toward sustainable development in defense of human rights, tolerance, and honesty and contributing to the creation of a proactive, productive, fair, and safe society. Furthermore, it is recognized by the civil security and safety system, food stipends, multi-classroom buildings, multi-laboratory buildings, sustainable kiosks, drinking fountains, and mobility that impact the economy and health of the University community.

In the first semester of 2020, the total enrollment comprised 96,409 students, $46 \%$ of them men and $54 \%$ of them women. 19,773 corresponded to high school and 76,736 to higher education. This enrollment represented $27 \%$ of the enrollment in higher education in the State of Puebla. Students were admitted from a pool of 91,670 applicants of which 73,727 were applying for undergraduate studies and 17,943 for high school studies, representing an increase of $48 \%$ over the previous year due to the elimination of fees in entrance examinations. It has presence in 24 of the 217 counties of Puebla through 5 regional complex facilities. Eighty-nine under and post graduate programs, of which five are offered as hybrid programs (part in person and part online) and eight virtually, comprise the academic offering available in a virtual and in person modes. Lastly, there is a base of 2322 online courses and 77 graduate programs (BUAP, 2019a).

The BUAP holds national and international standings due to the quality and relevance of its educational offerings and academic services that are supported by a solid and recognized academic staff. This staff is composed of more than 7000 faculty members who utilize relevant and flexible educational models that focus on the student, scientific and technological development, culture and the arts, and an academic structure that serves in national and international cooperation and collaboration networks. In addition, the administrative and management structure is nimble, functional, accredited, and flexible, supporting the academic work under a policy of transparency, accountability, and sustainable development.

The principles of the institution are autonomy, academic freedom, freedom of research, secular nature of education, quality and relevance, co-responsibility, high institutional performance, inclusion, social responsibility, and accountability.

The BUAP ranks sixth among the top 22 public and private Mexican universities, according to the Times Higher Education's Latin America University Rankings (2020), which recognizes its commitment to educational quality, scientific production, and academic achievement (BUAP, 2020). 
In order to fulfill its mission, the university has a strategic agenda embodied in the Institutional Development Plan 2017-2021 (IDP), which includes the following subjects: (1) educational offer; (2) admission, permanence, terminal efficiency, and graduation; (3) teaching; (4) research and graduate studies; (5) linkages and social responsibility; (6) positioning, visibility, and international quality; (7) maintenance and adaptation of educational infrastructure; and (8) management and governance (BUAP, n.d.-b).

\subsection{Support to K-12 Systems}

The accelerated pace of globalization and new developments have increased the importance of educating students toward the development of a society and a global consciousness in the context of interdependency between local events along with remote and global events. For example, education now involves developing skills to promote sustainable development and understanding this as meeting the needs of the present without compromising the ability of future generations to fulfill their own needs. This requires building an inclusive, sustainable, and resilient future for people and the planet and harmonizing economic growth, social inclusion, and environmental protection. These are interrelated and essential elements for the wellbeing of people and society.

The eradication of poverty in all its forms and dimensions is a prerequisite for achieving sustainable development. By promoting inclusive and equitable economic growth with enhanced opportunities for all, this will lead to reduced disparities, improved living standards, and enhanced equitable social development, which promotes ecosystem sustainability.

As a result, education in the twenty-first century requires an educational model that considers cooperative, project-based, and self-managed learning as well as critical and analytical thinking. In addition, it should consider the use of simulators and technology to foster the development of disciplinary and soft skills in the interpersonal and intrapersonal domains: leadership, responsibility, creativity, ethics, perseverance, functional mastery of digital knowledge, goal-oriented, oral and written communication skills, and teamwork (BUAP, 2019c). The challenge is to articulate the development of skills with the different learning contexts and methodologies.

The BUAP's IDP educational offer strategy, defined under the educational model and on the initiative of President Alfonso Esparza, has the following objectives: ensure relevance, respond to regional, national, and international needs for social and economic development, and promote graduate profiles that ensure the development of competencies associated with employability and entrepreneurship. This strategy fosters entrepreneurship, its culture, and an ecosystem that supports it, such as EmprendeBUAP. By awarding recognition to the achievement of competitiveness among entrepreneurs, BUAP is thus contributing to building a better world as 
well as cultivating creativity and innovation in the creation of solutions to problems locally and globally (BUAP, 2019b).

Two routes were proposed in the project: (1) entrepreneurship training and educational programs for all levels so that students receive the basic elements to undertake it according to their life and career plans and (2) support in the different stages of students' entrepreneurial projects for students interested in the entrepreneur's route. In both cases, the student is invited to identify a project aligned with the UN Sustainable Development Goals as a starting point.

The central question when undertaking this project is how to formulate a strategy in the face of an environment characterized by rapid technological change and high economic interdependence. VUCA, the acronym for Volatility, Uncertainty, Complexity and Ambiguity, was adapted to the context for students to work actively with a sense of urgency and a scarcity mindset. Online education was considered the best option for content development and training in entrepreneurship since it responds to the entrepreneurial context (BUAP, n.d.-a).

Process and impact indicators were established, including the percentage of programs offered in non-conventional modalities of students participating in entrepreneurship programs and of alumni who are company or business owners. An inter-functional committee was set up with the participation of the Vice-President of Academic Affairs, the Principal of High School Education, the Head of Community Work, Internships and Academic Affairs, and Alumni and Career Services Office; the Vice-President for Graduate School and Research along with the Innovation and Entrepreneurship Director; Communication and Information Technologies Director; and News and Communication Services Offices. The implementation of the program and operation of the committee was assigned by the President's office to the Student Affairs office. When the high school curriculum was updated in 2018, an opportunity to incorporate entrepreneurship training became apparent for the committee, which ensured that at the end of their high school studies, students would have the skills to develop their entrepreneurial project along with their soft skills.

Once the proposal was disseminated, the subject of entrepreneurship was incorporated to each of the six semesters of the curriculum, with the following general proposal: to promote a quality entrepreneurial education through developing the skills which an entrepreneur should possess, such as self-knowledge and resilience, understanding of value chain, and developing a business model. This is done through activities and cases that allow their identification and progress, integration of collaborative teams, and the cultivation of an entrepreneurial spirit in their family and social environments as much as in the academic one.

This course includes the following elements: critical thinking and problemsolving in which the student uses logical mathematical thinking and research methodology, teamwork, and collaboration. Here, the student participates, both individually and in teams, to propose alternatives to act and solve problems of social impact, allowing the students to develop a constructive and respectful behavior. Socio-emotional skills and their life project encourage self-knowledge and resilience, which allows them to discover themselves and find their internal strengths to face and solve problems in their environment. 
In the last President's report, the results of EmprendeBUAP are as follows: 172 faculty members have provided basic training in entrepreneurship to 16,400 students, of which 15,500 are from middle education and the remaining from 30 academic programs in higher education (Unidas Naciones, 2019).

\subsection{Actions During the Pandemic}

We are experiencing the biggest global education crisis ever with school systems and classes suspended in more than 170 countries. Around 1.6 billion students are out of school worldwide, 170 million in Latin America, and more than 35 million in Mexico. Lack of educational continuity is a silent crisis. As World Bank education expert Emanuela di Gropello says, it could have an impact on social mobility, poverty reduction, sustainable development, innovation and development, and care for the environment (Mundial Banco, 2020; Saavedra, 2020).

Faced with an unexpected event, school systems with their different capacities migrated from a face-to-face education model to a remote one. Moving education from the classroom to the home brings with it several challenging factors into consideration: the role of parents, computer availability and access for both the student and the faculty member, teacher training in digital competencies, and a platform and content relevant to the teaching-learning process.

In Mexico, $40 \%$ of the population have computer and Internet access at home. It is estimated that $50 \%$ of the country's educational institutions have the technology and resources to achieve a continuous education. In addition, there is currently an educational gap in our country in terms of coverage and quality. On the other hand, it is known that more than $90 \%$ of those between the ages of 18 and 26 have a device that connects them to the Internet (Secretaría de Educación Pública, 2020).

In view of this scenario, BUAP is considering its social commitment to take the opportunity to contribute. With its acquired experience and infrastructure, the university can contribute to the educational continuity of students in high school, both within the institution itself and of third parties.

Safeguarding the integrity of the university community and establishing actions for academic continuity are the priorities established by the BUAP, in high school education. Specifically, BUAP is focused on guiding the work and academic continuity, such as prompt communication of official information through social networks, video platforms, and "Course Management System" (CMS) to continuously inform the different actors of the community: students, faculty members, and parents.

One of the biggest challenges in the face of health contingencies is faculty professional development since the current modality is classroom-based. Through the Communication and Information Technologies Director, faculty members took part in a course on Microsoft Office 365 along with other content management system (CMS) platforms like Moodle. BUAP also met with the staff and academic leaders to discuss the various problems that arose in the regions of Puebla to take the necessary actions. 
Follow-up and monitoring of the academic activity help assure BUAP's essential function in the teaching and training the students. When faced with the situation where the student is at home, it is impossible to directly observe their actions, thus requiring an innovative approach. EmprendeBUAP's faculty called a meeting in the second week of March 2020 to implement the strategy for academic continuity, which included using the existing curriculum, migrating the subject of entrepreneurship from face-to-face instruction to online, and establishing a program to support teachers, parents, and students to address the following priority issues:

- What do I do with myself? This is done in the environment of uncertainty, addressing personal well-being, anxiety, and stress.

- What do I do with my training? This speaks to the continuity of training while facing unexpected change from a face-to-face model to an online one.

- What can I do to mitigate the effects of the crisis in my environment and in social, familial, and economic areas?

To migrate the subject, a team comprising high school principals, faculty members, instructional design specialists, and entrepreneurial consultants was created. They decided that each subject would comprise of 2 blocks, and each block would encompass the review of 16 activities. Differential elements like the use of the case method, simulators and exercises, conceptual maps, keynote speeches, virtual forums used for presenting projects, and an evaluation system to monitor knowledge, practice, and application were considered.

With the aim of supporting students, faculty members, and parents in mitigating the effects of the pandemic, the team developed the initiative: "Sal de la Curva, la otra cuarentena" (which translates as "get out of the curve, the other quarantine"). The team created and presented a prototype to businessmen, entrepreneurs, outstanding professionals, the media, and business chambers to validate the model, improving on it, and inviting them to take part. Because of this dialogue, it was considered appropriate to use the mentoring and master classes format to achieve an easy transfer from a theory of action and to encourage participation. This maintained a sequence which allows for the construction of meaningful learning, to select and train the mentors, to use straightforward and accessible virtual platforms, to spread through social networks, to carry out an advocacy campaign with business and civil society organizations, and to extend collaboration with other educational institutions.

Mentoring is offered through an online platform with a duration of 60 min under the following schedule: $5 \mathrm{~min}$ for a presentation followed of $30 \mathrm{~min}$ of exposition and finally 25 min of open forum with Q\&A session to address doubts, share experiences, and generate proposals for action. At the end, they are invited to answer to an evaluation.

Online master classes were carried out with the support of prominent entrepreneurs and business chambers. For example, "El sueño mexicano" (the Mexican dream) was taught by the prominent entrepreneur, Arnoldo de la Rocha, in alliance with the National Chamber of Restaurants and Seasoned Food Industry (CANIRAC) and a civil society organization. "Como emprender con sentido social" (how to be 
an entrepreneur with a social agenda) had the presence of the entrepreneur Juan Servitje in alliance with the international organization ENACTUS. "¿Cómo abordar la crisis en mi negocio?" (how to address the crisis in my business) included the participation of the entrepreneur Eugenio Cárdenas, president of "Unión Social de Empresarios Mexicanos" (USEM).

To increase the impact of these efforts, a partnership was established with the following institutions: Universidad de Costa Rica, Universidad D'Vinci and Universidad San Carlos de Guatemala, and the Universities of El Bosque, Minuto de Dios, and Santo Tomás in Colombia. In addition, there is a link with the "Unión Poblana de Escuelas Privadas" (UPEP), which includes 120 basic education schools. They were offered mentoring and master classes and a program for staff management of affiliated institutions covering issues of welfare, digital skills, and strategy and finance before Covid-19.

The offering of these courses, mentoring, and master classes are the product of the collaborative and supportive work of the directors of the faculties of Administration and Public Accounting, who contributed content and academic links; of the President of Higher Education with a team who worked on the development of lesson plans, teaching sequences, and content; of the Directorate General of Computing and Information Technology and Communications who led the platform, social network management, and educational technology for online instructional design; of the Director of Innovation and Knowledge Transfer with the link to the sectors, content, and its model of social entrepreneurship; of the Director of Community Work who focused on the UN Sustainable Development Goals; of the General Coordination of Student Affairs who supported the collaborative work between the parties; and of the support of the President's office to set the guidelines for achieving the mission and the IDP.

The initiatives were developed with the resources and infrastructure of BUAP along with the solidarity of teachers, mentors, businessmen, and entrepreneurs who donated their talent and time.

\subsection{Evaluation and Learning}

One of the lessons that BUAP has learned in considering entrepreneurship as a transversal competence is that one must act with a sense of urgency, use resources at hand in a rational and intelligent manner, develop prototypes, and pivot. Covid-19 tested the entrepreneurial spirit of the community. As the university was working in advance on an online course offering for undergraduate studies, this was seen as an opportunity to strengthen educational continuity and develop online courses with innovative and disruptive content.

The results are encouraging, with achievement percentages above $80 \%$ and $90 \%$ in the different indicators for the established action lines. Within 45 days of their conceptualization, the online subjects for higher education were developed and 
implemented. These are ready to be offered by the second semester and will reach 18,000 students.

85 mentoring sessions were conducted along with 6 master classes in the span of 11 weeks. It is estimated that 6000 people were reached, including students, teachers, and parents. Out of 893 responses received, 92\% expressed their satisfaction with the presented content, $89 \%$ with the mentoring dynamics, and $87 \%$ commented that they achieved significant and transferable learning. Ignacio Alarcón, President of the Business Coordinating Council of Puebla, stated:

A wise initiative of the BUAP to help counteract the effects of the pandemic we are experiencing and will continue to experience for several months and perhaps some years. 'Sal de la Curva,' provided information, knowledge, and competence so that students, teachers, parents, and businessmen became aware of the situation and, in an orderly fashion and working as a team, found the way to navigate during the pandemic and glimpse plans and actions to return to normal. I acknowledge the commitment of BUAP and the president with the society of Puebla and my gratitude to the whole team.

The UPEP, through the President of the Association Javier Osorio, reports it has achieved the participation of 100 directors and 1500 middle school students. This was very useful to adjust the dynamics of the mentoring, giving more agility and flexibility and encouraging active participation from the students.

\subsection{Future Plans}

The impact of the pandemic on the economic activity in Mexico has been very significant. The magnitude and characteristics of this impact can be identified in three distinct phases or stages.

In the first instance, there was an initial effect at the end of the first quarter of 2020 derived from the closure of several countries and the first disruptions in the productive processes and education.

In the second instance, economic activity in the country slowed down significantly because of the decision to suspend all activities considered as non-essential ("Jornada nacional de sana distancia").

A re-opening process that will be slower and more gradual than originally anticipated will define the third phase. In that sense, this third instance will not only be much longer than the previous ones, but its duration is, up to this moment, quite uncertain.

It is estimated that the drop in GDP in 2020 may fluctuate between $-8.5 \%$ and $-10.5 \%$. This has caused a significant contraction in formal employment and major changes in the composition of the labor force. A significant increase in total and extreme poverty rates is anticipated in the country. According to various estimates, around 9 million Mexicans may be considered poor, and a similar number might fall into extreme poverty (Esquivel, 2020).

The BUAP is aware of this complex situation and maintains its commitment to its mission, with the flexibility to adjust the strategic university agenda to the 
requirements that the situation demands. Thus, the institution made the decision to offer $100 \%$ of the online subjects and to share the study plans with the 34 incorporated high school institutions, benefiting over 10,000 students.

One of the main challenges to be addressed is the availability of computers and Internet access, particularly in the student world. According to OECD data, only $68 \%$ of students have an infrastructure of adequate quality, and therefore other means must be proposed to maintain equality of opportunity in education. BUAP has established a strategy to support those students who are in a vulnerable and unfavorable position in their economic situation to guarantee their online continuous education. Aware of this problem and to ensure equal opportunities and equity in 2020, all candidates for high school level will be accepted. In addition, there is an awareness of the new reality of the teacher who, in addition to training in digital skills, will require different counselling as they will be working from home in very different conditions to those encountered on campus and in the traditional classroom. Also, BUAP will keep in mind the need to seek alternative resources in the face of a possible decrease in public funding. Lastly, it is fundamental to keep strengthening the resilience, innovation, and the entrepreneurial capacity of the university ecosystem.

Acknowledgments The initiatives and actions expressed in this document would not have been possible without the participation and commitment of Dr. Alfonso Esparza, President of BUAP, and special thanks to the EmprendeBUAP team. We also thank the entrepreneurs Ignacio Alarcón, Arnoldo de la Rocha, Juan Servitje, and Eugenio Cárdenas and the 60 mentors who kindly cooperated with their talent and time.

\section{References}

BUAP. (n.d.-a). Emprendedor 2.0 Mi proyecto futuro: innovar y emprender.. Retrieved July 30, 2020, from http://ppead.buap.mx/

BUAP. (n.d.-b). Plan de desarrollo institucional (2017-2021). https://www.pdi.buap.mx/sites/ default/files/pdf/mayo2018/Agenda_Estrategica.pdf

BUAP. (2019a). Anuario Estadístico 2018-2019. https://pdi.buap.mx/sites/default/files/2019/ anuario18-19.pdf

BUAP. (2019b). EmprendeBUAP. https://emprende.buap.mx/

BUAP. (2019c). Modelo Educativo Académico. http://cmas.siu.buap.mx/portal_pprd/wb/DGES/ modelo_educativo_academico

BUAP. (2020, July 8). BUAP, sexta mejor universidad del país de acuerdo con el Latin America University Rankings 2020, de Times Higher Education. https:/www.boletin.buap.mx/node/1719

Esquivel, G. (2020). Los impactos económicos de la pandemia en México. https://www.banxico. org.mx/publicaciones-y-prensa/articulos-y-otras-publicaciones/\%7BD442A596-6F43D1B5-6686-64A2CF2F371B\%7D.pdf

Mundial Banco. (2020, June 10). La educación en América Latina enfrenta una crisis silenciosa, que con el tiempo se volverá estridente. https://www.bancomundial.org/es/news/ feature/2020/06/01/covid19-coronavirus-educacion-america-latina

Saavedra, J. (2020, March 30). Covid-19 y Educación: Algunos desafíos y oportunidades. Banco Mundial Blogs. https://blogs.worldbank.org/es/education/educationalchallenges-and-opportunities-covid-19-pandemic 
Secretaría de Educación Pública. (2020). Programa sectorial derivado del plan nacional de desarrollo 2019-2024. https://www.gob.mx/cms/uploads/attachment/file/562380/Programa_ Sectorial_de_Educaci_n_2020-2024.pdf

Unidas Naciones. (2019). Informe de los Objetivos de Desarrollo Sostenible. https://unstats. un.org/sdgs/report/2019/The-Sustainable-Development-Goals-Report-2019_Spanish.pdf

Rodolfo Zepeda Memije obtained a master's degree in Public Opinion and Political Marketing from the Benemérita Universidad Autónoma de Puebla. He received a degree in Environmental Engineering from BUAP. He is currently the General Coordinator of Student Affairs at the aforementioned university.

Roberto Quintero Vega is a doctoral candidate at Centro Internacional de Prospectiva y Altos Estudios, with an MBA and a master's degree in knowledge management.

He has postgraduate studies at Columbia Business School, IMDOSOC, and IPADE's AD2 program.

He has a law degree and a specialization in international law from UDLAP. He is currently an ENDEAVOR global entrepreneur and was awarded the National Entrepreneurship Award in Mexico.

$\mathrm{He}$ is also a former National President of the Social Confederation of Businessmen of Mexico and an international lecturer on entrepreneurship and corporate social responsibility.

Open Access This chapter is licensed under the terms of the Creative Commons Attribution 4.0 International License (http://creativecommons.org/licenses/by/4.0/), which permits use, sharing, adaptation, distribution and reproduction in any medium or format, as long as you give appropriate credit to the original author(s) and the source, provide a link to the Creative Commons license and indicate if changes were made.

The images or other third party material in this chapter are included in the chapter's Creative Commons license, unless indicated otherwise in a credit line to the material. If material is not included in the chapter's Creative Commons license and your intended use is not permitted by statutory regulation or exceeds the permitted use, you will need to obtain permission directly from the copyright holder. 